\title{
The review of medicines in the United Kingdom
}

\author{
K. WINSHIP ${ }^{1}$, D. HEPBURN ${ }^{1}$ \& D. H. LAWSON ${ }^{2}$ \\ ${ }^{1}$ Medicines Control Agency, 1 Nine Elms Lane, London SW8 5NQ and ${ }^{2}$ Glasgow Royal Infirmary, Glasgow G4 0SF
}

\section{Introduction}

Prior to the thalidomide tragedy the regulation of manufacture, distribution and advertising of medicines in the United Kingdom was relatively low-key. Proposed legislation which would have had a profound effect on medicines regulation was before Parliament on the day of the declaration of World War I and was never incorporated into Law (Mann, 1984). Not until the thalidomide tragedy did the public understand that manufacturers of medicines could market products without having to satisfy an independent body as to safety and efficacy (Penn, 1983). Because of public concern the Committee on Safety of Drugs, chaired by Sir Derrick Dunlop, was established in 1963 as an interim measure pending legislation to establish a formal legal framework for licensing new medicines in the United Kingdom. The Association of the British Pharmaceutical Industry and the Proprietary Association of Great Britain agreed to seek the advice of the Committee on Safety of Drugs on clinical trials and marketing of new drugs. A secretariat was provided and the Committee on Safety of Drugs began work in an advisory capacity in 1964, and continued in this way until the Medicines Act (1968) came into force on 1 September 1971. From this data all medicines have had to be licensed before they could be sold or supplied in the United Kingdom. New products for which licences are sought by the pharmaceutical industry are assessed as regards their safety, quality and efficacy by the Licensing Authority, a function which in normal circumstances is delegated to the Medicines Control Agency of the Department of Health. The Medicines Act precludes the Licensing Authority from considering need or cost in the decision to grant a product licence. The Act also envisages that the Licensing Authority, in the form of the Ministers of Health (and Agriculture) of the United Kingdom (together with the Secretaries of State of Scotland, Wales and Northern Ireland), may seek the advice of independent committees set up by the Medicines Act. The Licensing Authority is not compelled to seek such advice, is within its rights in rejecting it and has on rare occasions done so. The committees initially comprised the Medicines Commission (of which the first chairman was Sir Derrick Dunlop), the Committee on Safety of Medicines and the Veterinary Products Committee.

Once a formal mechanism for considering applications for product licences was established, the Licensing Authority granted a Product Licence of Right for all products already available for sale on 1 September 1971. These products were not assessed by the Licensing
Authority at that time, but manfuacturers were informed that they would be assessed later. There were 39,035 Product Licences of Right. Review of these products was already considered desirable within the United Kingdom, and became a requirement in 1973 when the United Kingdom joined the European Community. Directives EC 65/65 and 75/318 required that throughout the Community proprietary medicinal products granted licences before 22 November 1976 should be reviewed by 20 May 1990 . the Licensing Authority therefore set up a mechanism to review such products, and this included formation of the Committee on the Review of Medicines in 1975. The Committee on the Review of Medicines was to give advice when requested on the safety, quality and efficacy of any substance or article with a Product Licence of Right. The Committee on Dental and Surgical Materials was also formed in 1975 to advise on dental and surgical materials and ophthalmic products. This Committee deals with new product licence applications as well as Product Licences of Right within its area of expertise.

\section{Phases of the UK review of medicines}

The European Community Directives led to exclusion from the 1990 deadline review of homoeopathic products, blood products, vaccines, toxins, sera and radiopharmaceuticals, which accounted for some 6,000 of the Licences of Right. The remaining products with Licences of Right had to be reviewed within 15 years, with review resulting in either full product licences or lapse of the Licences of Right. If the Licence of Right lapsed, the product was taken off the market. The review process was undertaken in three phases.

\section{The systematic review}

Initially the review was organised in approximately 30 therapeutic categories such as analgesics, nonsteroidal anti-inflammatory drugs, psychotropics, vaccines and immunologicals. The active ingredients were considered initially, aiming to review claims for efficacy; dosage; the need for warnings; contraindications; adverse effects; and the need for restrictions on advertising or labelling. In addition guidelines on quality were produced. Antirheumatic agents were considered first in 1976, followed by analgesics and psychotropic drugs in 1977. Some immunological products were also considered. Priority 
was given to these classes of drugs because adverse drug reactions related to them were reported frequently. Sub-committees of experts were set up for each category. Provisional recommendations for comment by licence holders and representative organisations were followed by definitive recommendations for the active ingredients. These were then applied to individual products. Where all the requirements were met a reviewed licence was granted.

The Herbal Standards Sub-Committee of the Committee on Safety of Medicines also contributed to the review of Licences by Right. Recommendation for minimum specifications for herbal ingredients were drawn up and a large number of herbs were considered, including sassafras, berberis, broom, mistletoe and juniper.

This approach proved too slow because the process of consultation, amendment, and review of individual licences took much longer than predicted. In the first 3 years only one category of drug per year had been considered. Companies were frequently unwilling to accept recommendations for individual products despite earlier consultation, and appealed to the Committee on the Review of Medicines and on occasion to the Medicines Commission. The approach had to be modified.

\section{Streamlined systemic review}

A second phase of systematic review commenced in 1979, and allowed the Committee to consider individual products at a much earlier stage without prior consultation. There were some difficulties in maintaining consistency by this procedure, but it increased considerably the rate of review. At this time large-volume parenteral fluids were reviewed separately because of concerns about quality. During this phase phenactin was banned, bromides were disallowed and recommendations for barbiturates and benzodiazepines were published (CRM, 1979, 1980).

Publication of such Committee recommendations was abandoned subsequently as this open policy provoked much controversy and led to legal difficulties. It was thought to pre-empt negotiations with individual licence holders and to limit their right to appeal. At that time an accelerated review procedure was set up to ensure that dangerous products were not left unreviewed for long periods. All products awaiting review were categorised into three groups: 1) those with no obvious hazard, 2) those with no obvious safety or efficacy concern, 3) and those where safety and efficacy could present problems. Products in the last group were given priority and brought to the attention of the Committee on the Review of Medicines as rapidly as possible. Examples included aerosol products containing neomycin which had caused deafness in children; bismuth salts reported in France and Australia to have caused encephalopathy; and products containing metals such as arsenic, mercury, antimony, tin and lead, or other ingredients such as borax and camphor. Fully reviewed licences were still not being issued rapidly enough to meet the EC deadline, and the method of review was altered further.

\section{Third phase}

In the final phase prescription-only medicines were dealt with first and those sold over the counter later. The last group of applications was received in 1990 (Figure 1). During this phase, additional professional staff were allocated to the work by the Medicines Control Agency, and the procedural guidance revised in order to effect more rapid progress, especially in medical assessments. A more pragmatic approach to products with minor self-limiting indications was adopted (CRM, 1986) by negotiating with companies to remove unsubstantiated claims, reduce the number of active ingredients, and improve labelling and information. This approach made a major contribution to completing the Review within months of the European Community deadline.

\section{Operating policies of the Committee on the Review of Medicines}

After the systematic approach was abandoned no further Sub-Committees were appointed. Instead the Committee on the Review of Medicines obtained advice whenever required from existing Sub-Committees on Chemistry, Pharmacy and Standards, and Safety, Efficacy and Adverse Reactions. Cross-representation from the Committee on the Review of Medicines on these subcommittees and on the Committee on Safety of Medicines has fostered a consistent approach by the Licensing Authority to products submitted under the review procedure and new applications for product licences.

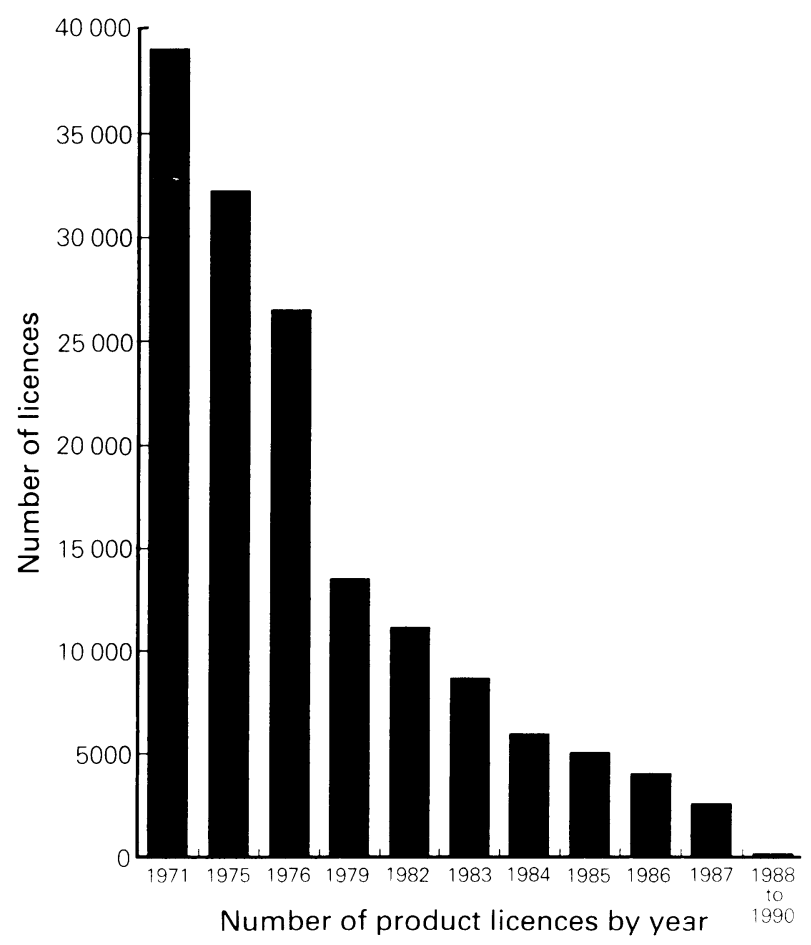

Figure 1 Number of product licences subject to review. 


\section{Number of products in the Review}

Of the initial 39,035 Licences of Right granted in 1971, 5,987 belonged to homoeopathic preparations, 207 to blood products, vaccines and immunologicals, and a further small number belonged to radiopharmaceuticals. All of these were excluded by European Community Directive $75 / 319$ from the requirement to review by 1990 , thus reducing by 6,194 the number of products to be reviewed by that date. In addition, 1,308 licences granted between 1971-1976 were brought into the review in 1983 as they required detailed assessment to ensure compliance with European Directive 75/318, for example, parenteral products and those with a low therapeutic ratio (Figure 1).

By the end of 1982, about 23,000 Licences of Right had been allowed to lapse by companies or been revoked by the Licensing Authority. Many licences were cancelled when companies were asked to submit information on products, such as details of composition or method of manufacture, which had not been presented or requested before. As requests for data became more detailed and product-specific during the third phase, $50 \%$ of the remaining licences were cancelled annually. The number of applications received and cancellation rate during this phase are given in Figure 2. By the end of 1988 the number of licences which had lapsed or been revoked had risen to 27,938 . Informal negotiations between companies and medical and pharmaceutical staff of the Medicines Control Agency as well as Committee action resulted in another 1,000 or so products being withdrawn from the market. Some of these products were withdrawn for commercial reasons.

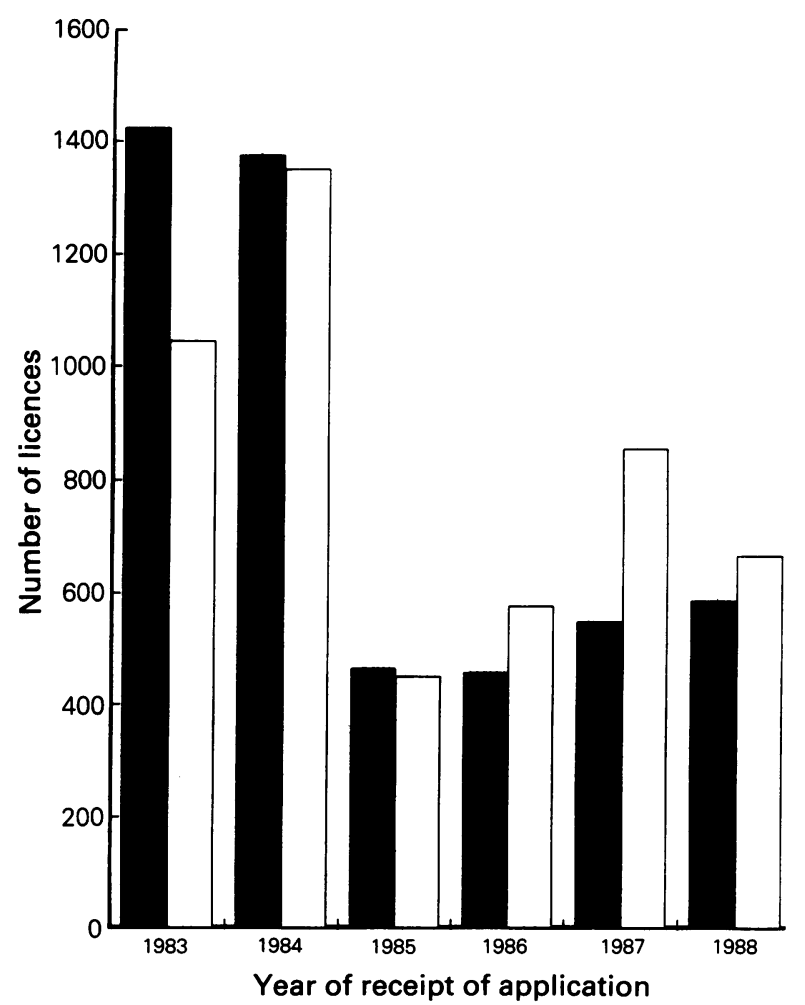

Figure 2 Cancellation and application rate of product licences. Third Phase, $\square$ Licences cancelled, $\square$ Applications received.

\section{Reviewed Product Licences}

Figure 3 shows the annual and cumulative total of reviewed licences issued. At the completion of the review in 1990 , less than 5,300 reviewed licences had been granted, many after changes had been agreed with the secretariat, out of 34,149 for review and 6,272 applications actually received. Eighty percent of the reviewed licences were issued in the final 5 years as the review gathered momentum to meet the European Community deadline. Of all the licences granted 3,000 were assessed by the medical and pharmaceutical staff during the final 4 years. This enchanced throughput was made possible by a number of policy reviews by the Committee on the Review of Medicines in the early and mid-1980s. In the assessment of safety, quality and efficacy it was evident that the interaction of pharmaceutical and medical aspects was especially important in reviewing the bioavailability of products such as digoxin and phenytoin. Many other pharmaceutical problems were concerned with stability, performance of sustained release products and the preservation of products during their shelf life.

Guidelines for routine assessment of a large number of products were undertaken. A list of some of the policy reviews is given in Table 1 . Guidelines set by the Committee on the Review of Medicines are still used by the staff of the Medicines Control Agency and the Committee on Safety of Medicines in the assessment of new products. The pregnancy warnings initially devised by Professor Peter Curzen are a particular example. The Committee on Dental and Surgical Materials also considered Licences of Right, and made specific recommendations for, among others, paste bandages,

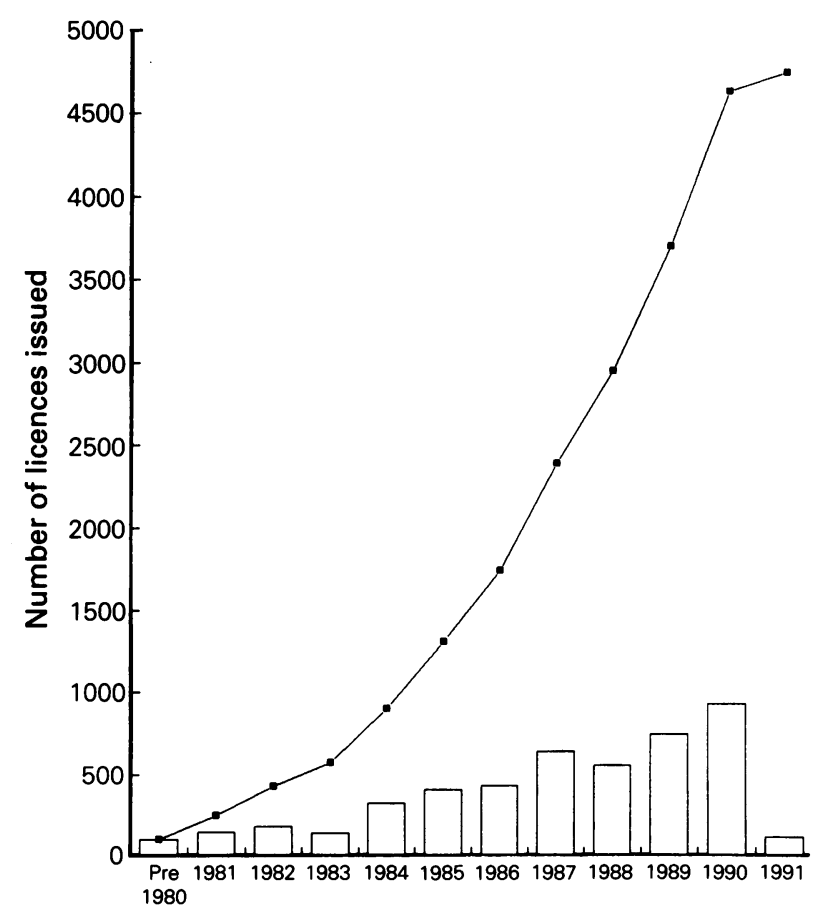

Figure 3 Reviewed product licences issued by year. $\square$ By year, $\rightarrow$ - Cumulative. 
Table 1 Some policy reviews by Committee on the Review of Medicines

Standardisation of pregnancy warnings on data sheets (Curzen)

Herbal products for self-limiting conditions

Bismuth salts

Camphor: indications and concentrations

Cold cure remedies

Comfrey: hazards

Corticosteroids: oral, injectable and topical

Cytotoxics: handling and reconstitution

Digoxin and bioavailability

Diuretics

Nitrofurantoin

Phenytoin and bioavailability

Preservation of antacid suspensions

Sucrose in paediatric medications

Sulphonamides

Tetracyclines

Unopposed oestrogens: toxicity

Vasodilators

label warnings for sympathomimetic eyedrops and sucrose in dental preventative products.

The use of precedent and, in particular, the policy reviews meant that overall the Committee on the Review of Medicines and the Committee on Dental and Surgical Materials were asked for advice on $706(11 \%)$ of the 6,272 applications, the majority being assessed by the Licensing Authority. Applications seen by the Committees were problematical ones which included difficult therapeutic issues, or which the assessors believed might have to be rejected. The annual number of applications for licences following review where advice was sought together with the frequency of appeals before the Committee on the Review of Medicines is shown in Figure 4. Sixty-two (8.8\%) of the applications placed before the Committees, went to an appeal before the Medicines Commission and of these $29(47 \%)$ were successful, generally following changes to the claimed uses, insertion of warnings and/or reformulation of the product.

\section{Committee structure}

The Committee on the Review of Medicines had approximately 15 members from medical and pharmacy specialties at any one time. The Committee on the Review of Medicines was chaired successively by four physicians, Sir Eric Scowen; Professor Owen Wade; Professor William Asscher and Professor David Lawson. The current chairman of the Committee on Dental and Surgical Materials is Professor Colin Berry. The Committee on the Review of Medicines was assisted by a full-time secretariat of physicians, pharmacists and

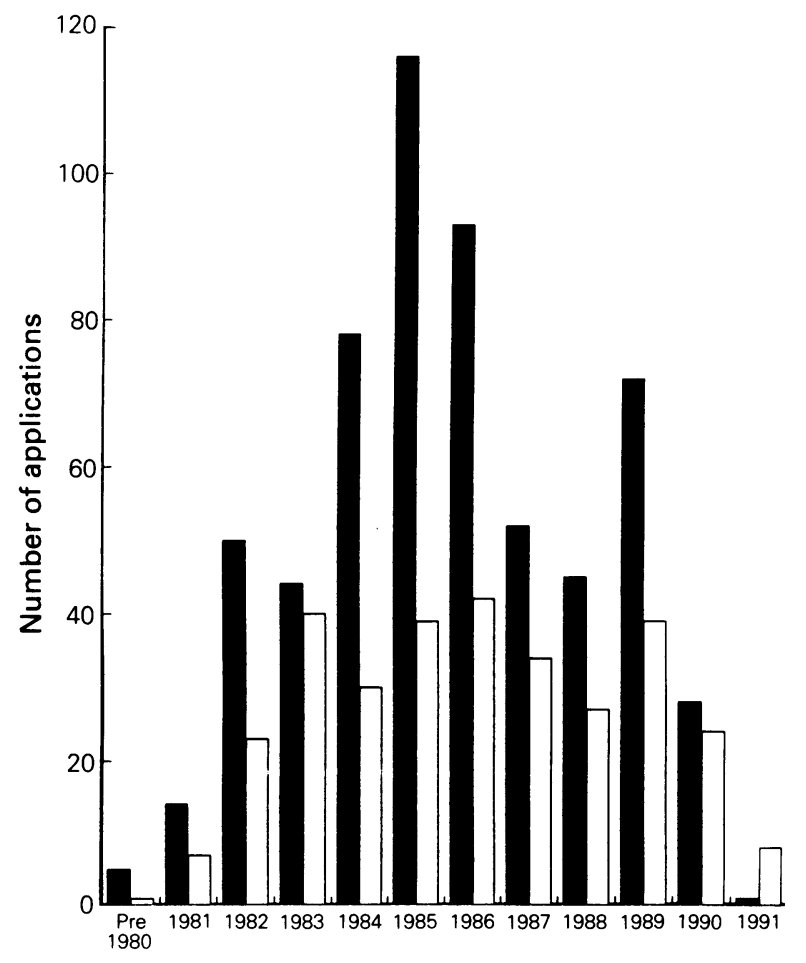

Figure 4 The work of the Committee on the Review of Medicines. Applications ( $\square$ ) and appeals ( $\square$ ).

administrators led by a secretary and senior medical and pharmaceutical assessors. The final senior officials were Mr Paul Winstanley (Secretary), Dr Kulsum Winship (Principal Medical Assessor), and Miss Doreen Hepburn (Pharmaceutical Assessor). The Medicines Control Agency provided the staff to support the Committees, to assess the applications, to discuss with the applicants, to organise sending to the companies invitations to apply, to register the applications and to issue reviewed licences. Secretarial staff also provided valuable support.

\section{Conclusion}

Although this major review has been successfully completed, urgent reviews of a particular drug or therapeutic category may be necessary at any time. In general, however, careful review of products at the time of renewal of product licences every 5 years should ensure that they remain in keeping with current clinical usage and acceptable quality standards.

Further European Community Directives approved in $1989,89 / 381$ for blood products, $89 / 342$ for immunologicals, and 89/343 for radiopharmaceuticals, require that the Directives shall be progressively extended to these products before 31st December 1992. They will bring into new review processes some 270 Licences of Right along with many other products which have already received full licences in the UK up to the time the Directives come into force. In addition a Homoeopathic Directive is in draft, which when finalised, will bring in for review the remaining Licences of Right. As the 
Medicines Control Agency discusses these additional tasks in the European Community Committee on Proprietary Medicinal Products, it is able fully to utilise

\section{References}

CRM (1979). Barbiturate review. Br. med. J., 2, 719-720.

CRM (1980). Systematic review of the benzodiazepines. $\mathrm{Br}$. med. J., 1, 910-912.

CRM update. (1986). Cleaning up the nation's medicine chest. Br. med. J., 292, 333.

Mann, R. D. (1984). Modern drug use, pp. 614-616. Lancaster: the experience it has already accrued and, consequently, is confident that procedures can be introduced which will deal expeditiously with the work that will arise.
MTP Press.

Penn, R. G. (1983). The review of medicines in the UK. Pharm. Int., 8, 205-210.
(Received 6 August 1991, accepted 5 December 1991) 